\title{
OPINION
}

\section{An old emperor finds new clothing: rejuvenation in our time}

\author{
David J Handelsman
}

Asian Journal of Andrology (2011) 13, 125-129; doi:10.1038/aja.2010.154; published online 22 November 2010

Those who don't understand their history are condemned to repeat it (Santayana)

History repeats itself, first as tragedy and then as farce (Marx)

$\mathrm{T}$ o cast this sage historical advice into contemporary terms, the eternal human predisposition to believe in flimsy promises of rejuvenation needs to be well understood, or repeated. As an ingenious species, we have made grand advances in overcoming the physical limits of our biology. Yet while technology has overcome our native ponderous, gravity- and land-bound locomotion with air, land and sea travel, the irreversibility of time and inevitability of death remain stubbornly unyielding. Even such prolongation of lifespan that we have achieved only reveals more starkly the progressive somatic decay and waning of virility which erode dreams of enduring youthful vigour. Lurking just below the conscious horizon, wishful thinking about rejuvenation regularly resurfaces whenever social conditions favour such indulgence. This ancient latent desire to reverse the effects of ageing, most prominently focused on male virility, has led to periodic eruptions of rejuvenation follyfalse hopes, built from dreams and armed with futile means, intent on reversing ageing. The epitome of rejuvenation follies is depicted in Lucas Cranach's sixteenth century fantasy landscape of the Fountain of Youth, the legendary spring waters that restore youthfulness, portraying wizened old crones entering a bathing pool to emerge as nubile youthful figures. Curiously, the painter's imagination considers it sufficient to rekindle flagging male virility for the object of libidinal interest to be rejuvenated without needing to revitalise the male body. The latter aspiration, however, gained greater attention in the most

ANZAC Research Institute, Sydney, NSW 2139, Australia

Correspondence: Professor D J Handelsman (djh@ anzac.edu.au) florid historical outburst of rejuvenation quackery originating over the turn of the twentieth century reaching an apogee over the next three decades before its rapid extinction. Serious, but self-deluded, doctors announced to great public acclaim various fanciful schemes starting with BrownSequard's injections of non-human testis extracts $^{1,2}$ and soon joined by Steinach's 'autoplastic' procedure (unilateral vasectomy) and Voronoff's testis grafts (stitching non-human testis slices onto the human testicular capsule). ${ }^{3}$ With the earnest selfbelief of pioneers proclaiming scientific triumphs, these doctors published their methods to allow for others to replicate reflecting fidelity in their motivation rather than hunger for limelight or enrichment. However, decades later, once the testosterone content of testes could be measured it was easily calculated or shown directly ${ }^{4}$ that Brown-Sequard's aqueous extract could yield no hydrophobic constituents such as testosterone. Like much good science, this realisation came too late to derail the flashy transit of hollow fashion. Consequently, Brown-Sequard's, as well as the associated millenarian fads, were simply placebos, mass delusions flourishing amongst a credulous public in thrall to the hubris of early medical science with its new temptation of scientific rejuvenation. Instinctively, contemporary medical journals deplored Brown-Sequard's claims as '.. recalling ... with an incredulous smile ...the wild imagings of medieval philosophers in search of an elixir vitae ...', disdaining his discovery as a 'Pentacle of Rejuvenescence ${ }^{5,6}$ (an ancient magical talisman consisting of a five-pointed star believed to summon energy.) and, presciently anticipating the placebo effects of expectation, recording that that the dramatic effects claimed in public displays could not be replicated in hospitalized patients. ${ }^{5}$ Nevertheless, the promise of revitalisation ensured enormous popularity for rejuvenation quackery ${ }^{1,2}$ until its abrupt eclipse in the 1930s. Thoughtful, scholarly scepticism is never much of a match for turbocharged optimism in the public arena regardless of the truth; and doctors, who always remain members of the community, are vulnerable to popular fashion and expectation. The demise and disappearance of rejuvenation quackery in the mid-1930s was due to the advent of the modern science of androgen pharmacology. This was signified by the 1935 virtual deadheated race between three industrial scientific groups, crowned by Nobel Prize recognition for two but curiously not the third, to fully characterize the major mammalian male hormone, which came to be named testosterone. $^{7-9}$ Hope never springs eternal more, it seems, than when it comes to rejuvenation.

\section{AN ILLUSION FINDS A DEFINITION}

A recent issue of New England Journal of Medicine (NEJM) publishes two closely related studies bookending the issue of testosterone administration to older men. This modern medical (re)incarnation of hormonal rejuvenation, with its scientific fixation on testosterone, has diverged during the last century from the ongoing non-medical lineage of rejuvenation follies which continue in the form of the expensive placebos of the Western health food supplement industry and Asian medicinal use of exotic animal body parts.

The concept of testosterone treatment for older men is based on considering male ageing as analogous to either menopause or 
pathologically-based hypogonadism. The former is a false analogy as menopause has a unique natural history featuring relatively abrupt and complete cessation of ovarian estrogen secretion in mid-adult life. This is contrary to all other human hormonal systems which decline gradually, modestly and inconsistently with ageing. This dichotomy always provided a firm basis for empirically testing the value of estrogen replacement for a state of uniform, complete estrogen deficiency. Nevertheless, the first randomized placebo-controlled clinical trial ${ }^{10}$ was preceded by decades of widespread overuse of estrogens for menopause which declined by $80 \%$ after the study's publication. ${ }^{11}$ This exuberant use was based on overinterpreted observational studies and fuelled by inflated expectations of not just symptomatic benefit, but of fundamental health benefits by modifying the natural history of major late-life fatal diseases of women. For all other agerelated declines in pituitary hormonal axes, there is no convincing evidence of medical benefit, and notably less enthusiasm, for correcting the modest age-related decreases in thyroid, adrenal or growth hormones compared with the popularity of testosterone for both men and women.

The other analogy, with pathologically based hypogonadism, is based on the superficial resemblance of non-specific symptoms of ageing but which are equally apparent in many other hormonal deficiency states as well as chronic non-gonadal diseases. This 'andropause hypothesis', known also by various synonyms 'male menopause', 'viropause', 'partial androgen deficiency of the ageing male' and 'late onset hypogonadism' or 'late-life onset hypogonadism' was so poorly substantiated that the authoritative 2004 US Institute of Medicine's review ${ }^{12}$ concluded that better preliminary evidence was required to warrant a large-scale prospective study comparable to the Women's Health Initiative for estrogen replacement in menopause. Nevertheless, the last two decades have seen a $\sim 20$-fold increase in testosterone prescribing in the absence of any proven new indications for testosterone treatment. This increase is largely confined to the United States with minimal changes in other regional markets; ${ }^{13}$ however, the 'andropause' bandwagon has undoubtedly left the station propelled by direct-to-public drug advertising.

One of the NEJM paper is from the European Male Ageing Study (EMAS), a large, well-designed observational study of male ageing involving over 3300 men drawn from population-based sources in eight
European cities. EMAS is the European counterpart of the seminal Massachusetts Male Ageing Study (MMAS) from the New England Research Institute in Boston which, in a series of memorable and widely cited papers (250 papers, with over 9000 citations so far) over the last two decades created the first sound basis for population-based research into reproductive and related general health aspects of male ageing. EMAS has now begun reporting a series of studies covering much the same territory with similar means but using a larger, multicentre approach in diverse European populations. ${ }^{14,15}$

This EMAS paper evaluated a wide range of non-specific physical and mental symptoms that accumulate during male ageing and focused on their relationship with blood testosterone levels. The approach of relating non-specific symptoms to serum testosterone levels originates from clinical studies that defined thresholds for symptoms of androgen deficiency in classical pathologically based hypogonadism using clinic-based, convenience populations ${ }^{16,17}$ an approach that was extended to population-based analysis of MMAS data seeking to define symptomatic age-related androgen deficiency among older men. ${ }^{18,19}$ An important caveat arising from detailed studies of individual men with authentic androgen deficiency is that, although individuals have highly consistent blood testosterone thresholds for symptoms, neither thresholds nor symptoms are consistent between individuals. ${ }^{16}$ Thus grouping individuals according to symptom(s) would encompass a wide range of individual blood testosterone thresholds so that averaged between-individual estimates of threshold would provide only a crude representation of the component, divergent individual thresholds.

On this background, the EMAS paper introduces a large, multicentre sample size; however, statistical power cannot overcome logical flaws. Examining a wide array of physical and questionnaire measures they found no significant association between physical or psychological features and blood testosterone levels. The analysis then focused on three sexual symptoms (erectile dysfunction, frequency of morning erections or sexual thoughts). Each exhibited a weak association with blood testosterone consisting of a shallow breakpoint (at levels of 8.0, 8.5 and $11 \mathrm{nmol} \mathrm{l}^{-1}$ ) together with high rates of false positive (25-50\%) and negatives (40-50\%) indicative of a weak positive and negative predictive values, although that predictive analysis was not reported. The only consistently significant association was between all three sexual symptoms and a blood total testosterone concentration threshold of $<8 \mathrm{nmoll}^{-1}$, but not $<11 \mathrm{nmol}^{-1}$. Yet, the paper proposes 'definition' that requires three sexual symptoms plus a higher blood testosterone, $<11 \mathrm{nmol}^{-1}$. Furthermore, these associations were all nullified by adjustment for age, obesity and coexisting illnesses indicating that they are due to confounding effects of underlying pathology rather than authentic relationships between those sexual symptoms and blood testosterone levels. A practical implication of this finding is that, among older men without known pituitary or testicular pathology, reduced blood testosterone is due to, and a marker for, their obesity and/ or coexisting illnesses. Hence to rectify any deficit in blood testosterone levels, if that is warranted, should be directed towards ameliorating the underlying cause rather than administration of testosterone.

The proposed definition of 'andropause' also relies on calculation of a 'free' testosterone. This variable has an unearned and largely unquestioned reputation as a superior measure of testosterone action. In reality it has a flimsy biological rationale and is usually derived from inaccurate and misleading calculations rather than actual measurements. The concept of 'free' testosterone arose in the 1970s as a term borrowed from the early days of modern clinical pharmacology when mutual displacement of drugs from circulating binding proteins was a contemporaneous explanation for drug interactions. Although that concept of 'free' drugs has long been superseded by more physiological explanations for drug interactions such as reciprocal effects on drug metabolizing enzymes, drug transporters and orphan receptors, ${ }^{20}$ the concept of 'free' hormones persisted in endocrinology where it passed from being an illustrative heuristic speculation to become an almost mystical axiom. In the EMAS paper, like most others using 'free' testosterone, this derived variable is calculated from the blood total testosterone and SHBG levels by a formula, often glorified as calculations using the 'Laws of Mass Action'. In reality, these calculations are poorly validated in large scale practical usage with substantial inaccuracies (20-40\% overestimation) compared with laboratory measurements of dialysable testosterone, the gold standard. ${ }^{21-23}$ Similar inaccuracies are present in the son-of-free testosterone, the 'bioavailable' testosterone. ${ }^{24}$ Such systematic errors are due to violations of the many assumptions in practical application of 
theoretical equilibrium binding equations, particularly inaccurate plug-in stoichiometry and binding affinity estimates although several other assumptions are questionable and unverified. Such errors render these convenient formulae unsuitable for use in individual diagnosis as the definition envisages $^{21-23}$ although the systematic error is better tolerated in self-contained research studies. The computational artefact of 'free' testosterone has introduced nothing but confusion into the field of male ageing. The heavy reliance of 'free' testosterone on blood SHBG levels which increases with age (and decrease with obesity, which in turn increases in prevalence with age) means that including 'free' testosterone in any model or formula merely re-introduces 'age' in a masked form that undoes attempts to adjust the models fully for confounding effects of age. Consequently, including 'free' testosterone in the proposed criteria for age-related androgen deficiency simply turns it into a circular definition.

The counterpart MMAS study shows that blood testosterone levels in older men are quite variable ${ }^{18}$ due to regression to the mean and other biological and measurement variability. This, together with common experience, has led to all clinical guidelines requiring at least two blood samples weeks apart to confirm sustained low blood testosterone. ${ }^{25-27}$ Hence, a proposed definition of age-related androgen deficiency based on a single blood sample is likely to be errorprone. Generally such observational studies are best considered hypothesis generating for an interventional study featuring randomization and placebo controls. In that context this proposed definition is premature as a longitudinal counterpart with serial blood sampling together with symptoms would be required to form more reliable and robust testable criteria than a cross-sectional snapshot based on a single blood sample. Beyond the difficulties of reliance on a single blood sample, the proposed definition requires testosterone measurements by mass spectrometry, a superior technology not yet widely available in routine pathology laboratories despite the established limitations of testosterone immunoassays. ${ }^{28-30}$

As men with pathologically-based androgen deficiency were excluded, the proposed definition of age-related androgen deficiency is inherently a pathologizing or medicalizing of ageing. As dubious as this may be, it might be substantiated if the key defining variable, blood testosterone levels, displayed a distinct bimodality with age; otherwise, such pursuit must revert to creating arbitrary cutpoints in a unimodal distribution as ultimately transpired in this paper.

Additional important feature of this analysis is its reliance on adjustment of models. The eight European cities contributing equally to EMAS include more (the United Kingdom, Belgium, Sweden, Italy and Spain) and less (Estonia, Poland and Hungary) affluent countries. The pooling of populations so widely divergent in culture, economic development and health profiles into a single quasinational entity is more a political identity statement, a genuflection to the EU funding agency, than fact or reasonable assumption. Elimination of important between-centre differences as mere nuisance variables may obscure more than it reveals, missing the trees for all that forest. The influence of this dubious homogenisation on the findings remains unclear.

Finally, a major issue is the overinterpretation of cross-sectional data to imply causality. Although quasi-longitudinal interpretation of cross-sectional studies is a major temptation in telescoping time into a quick snapshot compared with slow, costly longitudinal observations. Such transmutation of crosssectional data into quasi-longitudinal is especially unsound when the population is not at steady-state as blood testosterone levels show a downward temporal trends in European ${ }^{31}$ and American ${ }^{32}$ populations, probably due to the progressive increases in population obesity. The impact of the implied causality of this study should not be underestimated. Despite the ritual demurrals of not recommending testosterone for older men, this paper would inevitably encourage greater use of testosterone as an anti-ageing tonic. One needs to wait no longer to verify this prediction than to read the accompanying editorial which now considers it possible to make a 'well-established' diagnosis of age-related androgen deficiency. ${ }^{33}$

\section{AND THE CONSEQUENCES}

The second NEJM paper reports the premature termination of a randomized, placebo-controlled clinical trial of testosterone treatment in older men with limited mobility (Testosterone in Older Men (TOM)) for an excess of adverse cardiovascular effects in testosterone treated men. It is an interesting reflection on the contemporary risk-averse environment dominating clinical research and medical publishing that the adverse TOM study findings were published within 6 months of study termination whereas the EMAS study spent 2 years in revision.
The TOM study aimed to evaluate somatic benefits of 6 months of testosterone treatment in older men focusing on the muscular and motivational effects of testosterone in frail men over 65 years with lowered serum testosterone. As expected, such a group of frail, elderly men had high background prevalence of pre-entry cardiovascular disorder. This underlying cardiovascular disease is itself responsible for lowering the blood testosterone levels as a non-specific consequence of any chronic illness. Ultimately the TOM study was terminated by its Data Safety and Monitoring Board due to the progressive excess of cardiovascular (23 versus 5 discontinuations in a final study population of 209) as well as other adverse effects in the testosterone-treated men. Although the study's definition of cardiovascular safety was broad (including unexplained syncope and peripheral edema), the unexpected findings were consistent using various alternative definitions.

As the TOM study design was based on conventional masking, entry criteria, individual dose titration and monitoring, these findings can be reasonably interpreted as a low cardiovascular safety margin for frail, elderly men. This differs from previous placebocontrolled studies of testosterone in older men, comprising younger and less frail study populations, that did not report excess cardiovascular adverse events as summarized in systematic reviews ${ }^{34-36}$ or even in small 3 -month ${ }^{37,38}$ and $12-$ month $^{39}$ studies of men with cardiac failure. Nevertheless, these testosterone-related adverse findings cannot be regarded as entirely surprising given the well-known male excess of earlier onset, more severe cardiovascular disease ${ }^{40}$ together with the comprehensive refutation of the long dominant estrogen protection hypothesis. ${ }^{41}$

These cautionary findings put into perspective the frequently misinterpreted finding of low serum testosterone in men with cardiovascular disease. This regular association in observational studies has become overinterpreted as a risk factor (rather than a consequence), leading to prediction of beneficial (rather than adverse) effects of testosterone treatment. ${ }^{42-45}$ This complacency led to a misplaced focus on prostate cancer as the major risk of testosterone treatment in older men. ${ }^{35,36}$

This paper saliently highlights the important principle that relatively small adverse effects involving the most common cause of death-cardiovascular disease-overwhelms even substantial benefits on less common or non-fatal disorders. Hence, the TOM study's 
confirmation of improved limb muscular strength is overshadowed just as were proven reduction in bone fractures and colorectal cancer in the Women Health Initiative, the loss of highly effective, gastric sparing COX2 analgesics and restrictions on oral antidiabetic glitazones due to their adverse cardiovascular effects.

\section{REFLECTIONS}

These papers resonate with echoes of past mistakes. The focus of the EMAS paper on rejuvenating sexual function can be viewed as a reversion to historical type. Both papers are sadly redolent of the HRT saga in which excessive estrogen prescribing was encouraged for decades by overinterpreted observational studies which led to inflated expectations of improved cardiovascular and other objective health benefits rather than mere symptomatic relief. This exuberance was only curbed by the Women Health Initiative study, ${ }^{10}$ the first placebo-controlled randomized controlled trial, which provided a sharp reality check in refuting net health benefits and reducing recommended postmenopausal estrogen usage to symptomatic relief for the shortest time necessary. ${ }^{11}$ Lest we sleepwalk down that same path, hopefully it will not take decades before the 'andropause hypothesis' undergoes analogous rigorous testing.

Another historical echo is from the longrange consequence of using, and inevitably then overusing, clinical diagnostic tests simply because they are available. Decades ago when thyroid function tests first became widely available to evaluate thyroid disorders using immunoassays established in specialist hospital laboratories, inevitably out of curiosity these tests were used in hospitalized patients without thyroid disease. Many proved to have low serum thyroxine (T4) and even lower serum triiododthyronine (T3) without having any known thyroidal disease; furthermore when the patients recovered from the underlying illness, the thyroid function tests reverted to normal. In a classical confusion of means and ends, this came to be known as the 'sick euthyroid syndrome', loosely defined as a patient with abnormal thyroid function tests and a non-thyroidal illness, but without intrinsic thyroid disease. This terminology reflected a natural reluctance to treat such patients with thyroid hormones despite clearly abnormal blood thyroid function tests when there was no authentic thyroid pathology. It is now generally recognized that abnormal thyroid function tests in non-thyroidal illness are due to the effects of chronic illness and not hypothyroidism warranting replacement therapy. ${ }^{46,47}$ The increasing use of testosterone assays in nonreproductive disorders appears to be unwittingly repeating this misadventure with the invention of a 'sick eugonadal syndrome', yet another name for 'andropause'. The main difference is that the interest in rectifying reproductive function, with its immediate misidentification with male virility, attracts much greater popular attention than for hypothyroidism.

These papers shine a spotlight on the limitations of clinical best practice guidelines over the last decade. Rather than serving to strengthen evidence-based medicine by restraining unproven overuse, they have become weakened and even eventually a collusive means of sanctioning it. Whereas the first national guidelines for testosterone use published at the start of the decade ${ }^{25}$ aimed to restrict testosterone prescribing for the unproven age-related androgen deficiency without hindering prescribing for pathologically based androgen deficiency, these were followed by European-based guidelines in 2005 and US guidelines in 2006, republished recently essentially unchanged. ${ }^{26,27}$ The latter blurred the distinction between pathologically-based and age-related androgen deficiency, loosening the diagnostic criteria and lacking regulatory force. As such they came to constitute a minimal diagnostic barrier that tacitly collude with rather than deter testosterone misuse. Whether this perverse outcome is an unintended consequence of the failures of the guideline mechanism, ${ }^{48}$ or to the connivance of industry-friendly lobbying eroding guideline development is unclear.

These studies are a reminder of the undesirability of direct-to-public advertising of testosterone. Among all therapeutics, the advertising maxim that 'sex sells' makes testosterone the most vulnerable to the distortions and confected needs, which are the stock-in-trade of professional marketing of drugs to a public lacking the crucial and technical awareness required to appraise such manipulation. Without protection against this form of manipulative marketing, an avalanche of misguided testosterone prescribing awaits to distort the health and medical care of ageing men.

Ultimately, testosterone prescribing for older men should be restricted to careful clinical trials where diligent ethical oversight will ensure adequate design and suitable warnings to participants. The lowering of blood testosterone in older men due to their concomitant illnesses provides simultaneously both the opportunity for benefit as well as the risk of adverse cardiovascular outcomes. Nevertheless, such concerns should not be a barrier to necessary further research aiming to better define the benefits and risks of testosterone in older men. While age alone may not prove a valid indication for testosterone treatment, more specific studies examining the effects of testosterone on the co-morbidities of ageing such as obesity, diabetes and metabolic syndrome are still warranted. Crucially there is no reason to doubt they can still be safely performed within the framework of placebo-controlled, randomized clinical trials. Rather than the dubious pursuit of pathologizing of ageing, the evaluation of whether testosterone may have a role in adjunctive treatment of obesity, diabetes, metabolic syndrome or other chronic nongonadal diseases by rigorous interventional studies featuring randomisation and placebo controls, appear justified by a variety of observational studies. ${ }^{49-51}$

In their wider impact, these two studies can be construed as pressing the accelerator and the brakes at the same time on testosterone prescribing for older men... with probably the same effect of spinning wheels without moving forward. ${ }^{52}$ The challenge remains whether we can break free from the seemingly irresistible pull into a familiar downward spiral to learn from history rather than blindly repeating it.

\section{COMPETING FINANCIAL INTERESTS}

I have received consultancy fees from Clarus Therapeutics and Radius for advising United States companies on androgens. My institution has received funding from Bayer Schering Pharma and Ascend for investigator-initiated research.

1 Borell M. Brown-Sequard's organotherapy and its appearance in America at the end of the nineteenth century. Bull Hist Med 1976; 50: 309-20.

2 Borell M. Organotherapy, British physiology, and discovery of the internal secretions. J Hist Biol 1976; 9: 235-68.

3 Kahn A. Regaining lost youth: the controversial and colorful beginnings of hormone replacement therapy in aging. J Gerontol A Biol Sci Med Sci 2005; 60: 142-7.

4 Cussons AJ, Bhagat Cl, Fletcher SJ, Walsh JP. BrownSequard revisited: a lesson from history on the placebo effect of androgen treatment. Med J Aust 2002; 177: 678-9.

5 Anonymous. Dr Brown-Sequard's 'Elixir of Life'. Lancet 1890; 135: 57-8.

6 Anonymous. The pentacle of rejuvenescence. $\mathrm{Br} \mathrm{Med}$ J 1889; 1: 1416.

7 Butenandt A, Hanisch G. Uber die Umwandlung des Dehydroandrosterons in Androstenol-(17)-one-(3) (Testosterone); Umweg zur darstellung des 
testosterons aus Cholsterin (vorlauf mitteilung). Zeischrift Physiologische Chemie 1935; 237: 89-97.

8 David K, Dingmanse E, Freud J, Lacqueur E. Uber krystallinisches mannliches Hormon aus Hoden (Testosteron), wirksamer als aus Harn oder aus Cholestrin bereites Androsteron. Zeischrift Physiologische Chemie 1935; 233: 281-2.

9 Ruzicka L, Wettstein A. Uber die krystallische Herstellung des Testikelhormons, Testosteron (androsten-3-on-17-ol). Helv Chim Acta 1935; 18 1264-75.

10 Rossouw JE, Anderson GL, Prentice RL, LaCroix AZ, Kooperberg $\mathrm{C}$ et al. Risks and benefits of estrogen plus progestin in healthy postmenopausal women: principal results from the Women's Health Initiative randomized controlled trial. JAMA 2002; 288: 321 33.

11 Santen RJ, Allred DC, Ardoin SP, Archer DF, Boyd N et al. Postmenopausal hormone therapy: an Endocrine Society scientific statement. J Clin Endocrinol Metab 2010; 95: s1-s66.

12 Liverman CT, Blazer DG. Testosterone and Aging: Clinical Research Directions. In: Board on Health Sciences Policy. Washington DC: Institute of Medicine/The National Academies Press; 2004. p217.

13 Handelsman DJ. Trends and regional differences in testosterone prescribing in Australia: 1991-2001. Med J Aust 2004; 181: 419-22.

14 Tajar A, Forti G, O'Neill TW, Lee DM, Silman AJ et al. Characteristics of secondary, primary, and compensated hypogonadism in aging men: evidence from the European Male Ageing Study. J Clin Endocrinol Metab 2010; 95: 1810-8.

15 Wu FC, Tajar A, Pye SR, Silman AJ, Finn JD et al. Hypothalamic-pituitary-testicular axis disruptions in older men are differentially linked to age and modifiable risk factors: the European Male Aging Study. J Clin Endocrinol Metab 2008; 93: 2737-45.

16 Kelleher S, Conway AJ, Handelsman DJ. Blood testosterone threshold for androgen deficiency symptoms. J Clin Endocrinol Metab 2004; 89 3813-7.

17 Zitzmann M, Faber S, Nieschlag E. Association of specific symptoms and metabolic risks with serum testosterone in older men. J Clin Endocrinol Metab 2006; 91: 4335-43.

18 Travison TG, Shackelton R, Araujo AB, Hall SA, Williams RE et al. The natural history of symptomatic androgen deficiency in men: onset, progression, and spontaneous remission. J Am Geriatr Soc 2008; 56: 831-9.

19 Mohr BA, Guay AT, O'Donnell AB, McKinlay JB. Normal, bound and nonbound testosterone levels in normally ageing men: results from the Massachusetts Male Ageing Study. Clin Endocrinol (Oxf) 2005; 62 64-73.

20 Part I. General Principles, Chapters 2, 3 and 5. 11th ed. New York: McGraw-Hill; 2006.

21 Ly LP, Handelsman DJ. Empirical estimation of free testosterone from testosterone and sex hormonebinding globulin immunoassays. Eur J Endocrinol 2005; 152: 471-8.
22 Ly LP, Sartorius G, Hull L, Leung A, Swerdloff RS et al. Accuracy of calculated free testosterone formulae in men. Clin Endocrinol (Oxf) 2010; 73: 382-8.

23 Sartorius G, Ly LP, Sikaris K, McLachlan R, Handelsman DJ. Predictive accuracy and sources of variability in calculated free testosterone estimates. Ann Clin Biochem 2009; 46: 137-43.

24 Egleston BL, Chandler DW, Dorgan JF. Validity of estimating non-sex hormone-binding globulin bound testosterone and oestradiol from total hormone measurements in boys and girls. Ann Clin Biochem 2010; 47: 233-41.

25 Conway AJ, Handelsman DJ, Lording DW, Stuckey B, Zajac JD. Use, misuse and abuse of androgens: The Endocrine Society of Australia consensus guidelines for androgen prescribing. Med J Aust 2000; 172 220-4.

26 Wang C, Nieschlag E, Swerdloff R, Behre HM, Hellstrom WJ et al. Investigation, treatment, and monitoring of late-onset hypogonadism in males: ISA, ISSAM, EAU, EAA, and ASA recommendations. $J$ Androl 2009; 30: 1-9.

27 Bhasin S, Cunningham GR, Hayes FJ, Matsumoto AM, Snyder PJ et al. Testosterone therapy in men with androgen deficiency syndromes: an Endocrine Society clinical practice guideline. J Clin Endocrinol Metab 2010; 95: 2536-59.

28 Taieb J, Mathian B, Millot F, Patricot MC, Mathieu E et al. Testosterone measured by 10 immunoassays and by isotope-dilution gas chromatography-mass spectrometry in sera from 116 men, women, and children. Clin Chem 2003; 49: 1381-95.

29 Wang C, Catlin DH, Demers LM, Starcevic B, Swerdloff RS. Measurement of total serum testosterone in adult men: comparison of current laboratory methods versus liquid chromatographytandem mass spectrometry. J Clin Endocrinol Metab 2004; 89: 534-43.

30 Sikaris K, McLachlan RI, Kazlauskas R, de Kretser D, Holden CA et al. Reproductive hormone reference intervals for healthy fertile young men: evaluation of automated platform assays. J Clin Endocrinol Metab 2005; 90: 5928-36.

31 Andersson AM, Jensen TK, Juul A, Petersen JH, Jorgensen $\mathrm{T}$ et al. Secular decline in male testo sterone and sex hormone binding globulin serum levels in Danish population surveys. J Clin Endocrinol Metab 2007; 92: 4696-705.

32 Travison TG, Araujo AB, Hall SA, McKinlay JB. Temporal trends in testosterone levels and treatment in older men. Curr Opin Endocrinol Diabetes Obes 2009; 16: 211-7.

33 Bremner WJ. Testosterone deficiency and replacement in older men. N Eng/ J Med 2010; 363: 189-91.

34 Calof OM, Singh AB, Lee ML, Kenny AM, Urban RJ et al. Adverse events associated with testosterone replacement in middle-aged and older men: a meta-analysis of randomized, placebo-controlled trials. J Gerontol A Biol Sci Med Sci 2005; 60 1451-7.

35 Haddad RM, Kennedy CC, Caples SM, Tracz MJ, Bolona ER et al. Testosterone and cardiovascula risk in men: a systematic review and meta-analysis of randomized placebo-controlled trials. Mayo Clin Proc 2007; 82: 29-39.

36 Fernandez-Balsells MM, Murad MH, Lane M Lampropulos JF, Albuquerque $\mathrm{F}$ et al. Clinical review 1: Adverse effects of testosterone therapy in adult men: a systematic review and meta-analysis. J Clin Endocrinol Metab 2010; 95: 2560-75.

37 Pugh PJ, Jones RD, West JN, Jones TH, Channer KS Testosterone treatment for men with chronic heart failure. Heart 2004; 90: 446-7.

38 Caminiti G, Volterrani M, lellamo F, Marazzi G, Massaro $\mathrm{R}$ et al. Effect of long-acting testosterone treatment on functional exercise capacity, skeletal muscle performance, insulin resistance, and baroreflex sensitivity in elderly patients with chronic heart failure a double-blind, placebo-controlled, randomized study. J Am Coll Cardiol 2009; 54: 919-27

39 Malkin CJ, Pugh PJ, West JN, van Beek EJ, Jones TH et al. Testosterone therapy in men with moderate severity heart failure: a double-blind randomized placebo controlled trial. Eur Heart J 2006; 27: 57 64.

40 Kalin MF, Zumoff B. Sex hormones and coronary disease: a review of the clinical studies. Steroids 1990; 55: 330-52.

41 Liu PY, Death AK, Handelsman DJ. Androgens and cardiovascular disease. Endocr Rev 2003; 24: 31340 .

42 Nettleship JE, Jones RD, Channer KS, Jones TH. Testosterone and coronary artery disease. Front Horm Res 2009; 37: 91-107.

43 Maggio M, Basaria S. Welcoming low testosterone as a cardiovascular risk factor. Int J Impot Res 2009; 21 261-4.

44 Bassil N, Morley JE. Late-life onset hypogonadism: a review. Clin Geriatr Med 2010; 26: 197-222.

45 Yeap BB. Androgens and cardiovascular disease. Curr Opin Endocrinol Diabetes Obes 2010; 17: 269-76.

46 Wartofsky L, Burman KD, Ringel MD. Trading one 'dangerous dogma' for another? Thyroid hormone treatment of the 'euthyroid sick syndrome'. J Clin Endocrinol Metab 1999; 84: 1759-60.

47 Adler SM, Wartofsky L. The nonthyroidal illness syndrome. Endocrinol Metab Clin North Am 2007 36: 657-72, vi.

48 Shackelton RJ, Marceau LD, Link CL, McKinlay JB The intended and unintended consequences of clinical guidelines. J Eval Clin Pract 2009; 15: 1035-42.

49 Zitzmann M. Testosterone deficiency, insulin resistance and the metabolic syndrome. Nat Rev Endocrinol 2009; 5: 673-81.

50 Mah PM, Wittert GA. Obesity and testicular function. Mol Cell Endocrinol 2010; 316: 180-6.

51 Grossmann M, Gianatti EJ, Zajac JD. Testosterone and type 2 diabetes. Curr Opin Endocrinol Diabetes Obes 2010; 17: 247-56.

52 Handelsman DJ. Testosterone and male ageing spinning the wheels. Med J Aust2010; 193: 379-80. 